
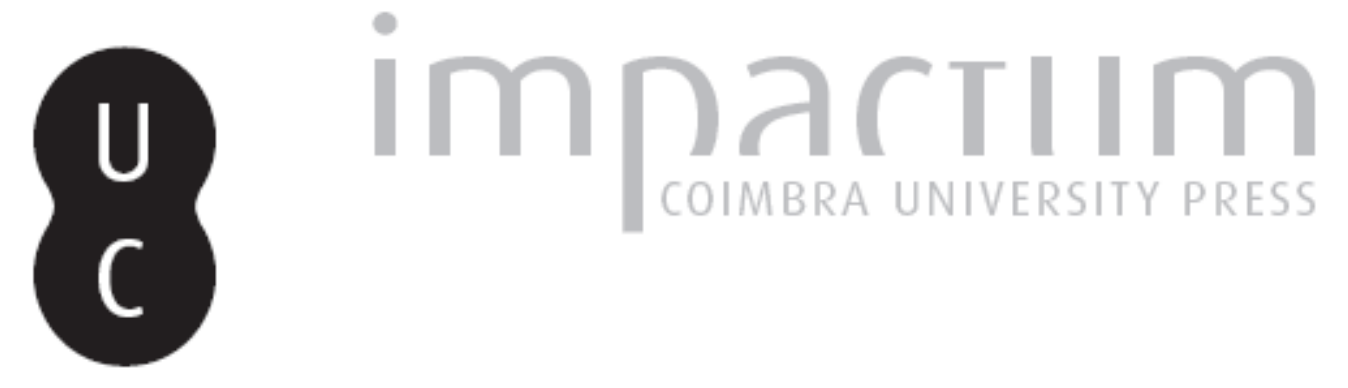

\title{
A geotermia: riscos e impactes ambientais: um exemplo da exploração de energias alternativas associadas ao vulcanismo
}

Autor(es): Raposo, António Guilherme Bettencourt

Publicado por: Associação Portuguesa de Riscos, Prevenção e Segurança

URL persistente:

URI:http://hdl.handle.net/10316.2/36154

DOI:

DOI:http://dx.doi.org/10.14195/1647-7723_16_11

Accessed : $\quad$ 26-Apr-2023 16:02:49

A navegação consulta e descarregamento dos títulos inseridos nas Bibliotecas Digitais UC Digitalis, UC Pombalina e UC Impactum, pressupõem a aceitação plena e sem reservas dos Termos e Condições de Uso destas Bibliotecas Digitais, disponíveis em https://digitalis.uc.pt/pt-pt/termos.

Conforme exposto nos referidos Termos e Condições de Uso, o descarregamento de títulos de acesso restrito requer uma licença válida de autorização devendo o utilizador aceder ao(s) documento(s) a partir de um endereço de IP da instituição detentora da supramencionada licença.

Ao utilizador é apenas permitido o descarregamento para uso pessoal, pelo que o emprego do(s) título(s) descarregado(s) para outro fim, designadamente comercial, carece de autorização do respetivo autor ou editor da obra.

Na medida em que todas as obras da UC Digitalis se encontram protegidas pelo Código do Direito de Autor e Direitos Conexos e demais legislação aplicável, toda a cópia, parcial ou total, deste documento, nos casos em que é legalmente admitida, deverá conter ou fazer-se acompanhar por este aviso.

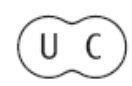




\section{territorium}

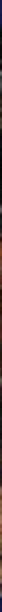

16

Revista da Associação Portuguesa de Riscos, Prevenção e Segurança 2009 
territorium 16

\title{
A GEOTERMIA: RISCOS E IMPACTES AMBIENTAIS. UM EXEMPLO DA EXPLORAÇÃO DE ENERGIAS ALTERNATIVAS ASSOCIADAS AO VULCANISMO*
}

\author{
António Guilherme Bettencourt Raposo \\ Geógrafo \\ agbraposo@gmail.com
}

\begin{abstract}
RESUMO
Decorria o ano de 1988 quando nos deslocámos à Reserva Natural da Lagoa do Fogo e nos deparámos com grandes dbras de remoção de terras, alteração de taludes e abate de árvores. Todos os materiais estavam a ser lançadbs para a bacia hidrográfica da Ribeira Grande onde, a jusante, se situa esta cidade. Toola esta intervenção ocorreu a uma altitude de 550 metros, ande as precipitações são da ordem das 2500 a 3500 l/m2 por ano, tendb sido criado um grave problema para o ambiente à escala local. Esta situação originou a degradação de uma parte da Reserva Natural, através da contaminação das águas das nascentes para abastecimento público e, ainda, uma crise sísmica, criandb o risco de uma enupção freática e, mesmo, de inundações.
\end{abstract}

Palavras chave: Geotermia, vulcanismo, impactes ambientais, degradação da paisagem.

\section{RÉSUMÉ}

Pendant l' an 1988, dans une visite à la Reserva Natural da Lagoa do Fogo, nous avons vu de grands travaux parr retirer de gros morceaux de terres, avec changement de pente et arrachement d' arbres. Tous les matériaux ont été jetés dans le bassin de la Ribeira Grande, à l' aval de la ville. Tates ces actions ont eu lieu à une altitude de 550 mètres, où la pluvionétrie est de l'ordre de 2500 à 3500 l/m2 anmuelles, ayant été créé un grave problème environnemental au niveau local. Cela a entraîné la dégradation d'une partie de la Réserve Naturelle, par la contamination des sarrces d' eau pour l'approvisionnement public, et aussi une crise sismique, le risque d'une éruption des eaux satterraines, et même les inondations.

Mbts-clé: Géothermie, volcanisme, impactes environnementaux, dégradation du paysage.

\section{ABSTRACT}

In the course of 1988 when we visited the Natural Reserve of Lagoa do Fogo we became aware of massive works of soil removal, slope alterations and tree felling. All the materials were discarded into the hydrographic basin of the Ribeira Grande downstream, where this city is located. All this intervention which ocarred at an altitude of 550 meters, where rain fall is abatt 2500 to 3500 l/m2 per year, created a seriaus local enviramental problem. This situation originated a degradation of a part of the Natural Reserve, contamination of spring waters for public consumption and still a seismic crisis, creating the risk of a phreatic enuption and even floods.

Key words: Geothermy, volcanism, envirorment impacts, landscape degradation. 


\section{Introdução}

O Arquipélago dos Açores, situado na área de junção de três grandes placas oceânicas, a Erroasiática, a Africana e a Americana, é uma região vulcânica altamente rica em rearsos naturais, sendb, em particular, uma fonte energética, pela possibil idade de exploração da energia geotérmica.

Ora, por não ser poluente, a exploração e aproveitamento desta energia deverá ter o apoio de todos. Mas, quando a possibilidade da sua exploração não é devidamente estudada e acompanhada por uma equipa pluridisciplinar, podem surgir consequências imprevisíveis em termas de manifestação das riscos que comporta.

No caso concreto da exploração geotérmica na itha deS. Miguel, os trabalhos realizados em 1988 foram executados numa Reserva Natural sem que tivessem sido tomadas certas medidas preventivas, designadamente a caracterização física do espaço geográfico destinadb a receber um empreendimento de grande envergadura como foi este. Com efeito, não houve o devido conhecimento e acompanhamento por parte da Secretaria Regional do Ambiente e, consequentemente, toob o processo decorreu sema sua intervenção, devido à pol ítica economicista da época.

Passados 20 anos, impõe-se uma reflexão: Será que as erros que foram cometidos e contabilizados servirão para, mais tarce, não voltarema ser repetiobs em situações ou empreendimentos pasteriores?

Para se estudarem os riscos e os impactes ambientais provocados pela exploração geotérmica na ilha de S. Miguel (Arquipélago dos Açores) e para que se compreenda o funcionamento das Centrais Geotérmicas da Ilha há que, em primeiro lugar, aprofundar as processos da Geotermia.

Será abordado em seguida o caso concreto, ocorrido no passado, há vinte anos, da exploração geotérmica na Reserva Natural da Lagoa do Fogo e suas consequências imediatas, para se poder analisar opresente e perspectivar o futuro.

\section{A Energia Geotérnica}

A exploração de um recurso geotérmico pressupõe quatro requisitos fundamentais:

i. Uma fonte de calor que poderá ser um campo magnético ou rochas quentes;

I) Um fluido transportador do calor;

III) Uma sequência de rochas permeáveis funcionando como reservatório;

ì Uma formação geológica impermeável e isolante de cobertura (Cap Rock) .

Os recursos hidrotermais são classificados de acordo com a entalpia específica do fluido, sendo de baixa entalpia as que têm temperaturas entre $30^{\circ} \mathrm{e}$ $120^{\circ}$ e os de alta entalpia temperaturas superiores a $120^{\circ}$. São estes que têm viabilidade de gerar energia geotérmica e electricidade (fig. 1) .

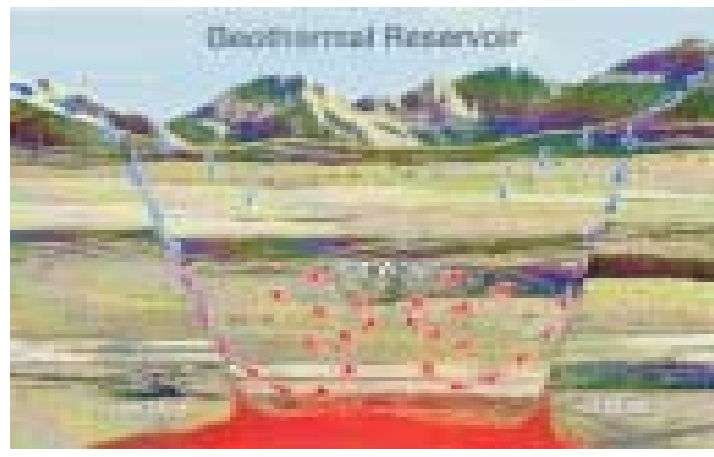

Fig. 1 - Modelo conceptual de um reservatório geotérmico (Geothermal Education Office/U.S. Department of Energy) .

Esta energia endógena que toma o nosso planeta geologicamente dinâmico, é responsável pelos processos dos movimentos das placas tectónicas, por fenómenos de vulcanismo ou pela ocorrência de sismos.

A localização dos campos geotérmicos, de acordo com a conhecida Teoria da Tectónica de Placas Litosféricas, está condicionada pelo modelo geodinâmico da Terra.

Os campos geotérmicos de alta entalpia estão relacionados com fluxas de calor elevados que se podem encontrar nas cristas médio-oceânicas (Açores ou Islândia), nas zonas de subotucção camo as arcos de i lhas vulcânicas (Japão, Indonésia) , ou ainda em zonas de riftingcontinental (Quénia, Eritreia) .

Os campos geotérmicas de baixa entalpia estão localizados nas zonas de fluxo de calor normal, em zonas calmas e interiores das continentes.

Os principais benefícios da Energia Geotérmica resultam de se tratar de uma energia não poluente comparada com as energias que utilizam combustíveis fósseis, ređuzindo as emissões as emissões de gases de estufa. Além disso, as centrais geotérmicas operam continuamente, sem estarem sujeitas a condições meteorrológicas, ao contrário das centrais eólicas e hídricas que estão dependentes da volati i idade do rearso.

A prospecção de recursas geotérmicas baseia-se em estudos no domínio da Geofísica, Geoquímica e Geologia, entre outros, e envolve diversas etapas, sendo a primeira o reconhecimento do campo, daí resultandb a exclusão de várias hipóteses. Nesta etapa escolhem-se áreas promissoras, seleccionandb-se locais para a execução de poças exploratórios profundos.

Finalmente, na fase de viabilidade procura-se caracterizar ofluidb geotérmicoe, emalguns projectos, procede-se à instalação de uma central piloto. 


\section{Os recursos geotérmicos dos Açores}

O facto de os Açores estarem situados na Crista Médio Atlântica proporciona uma intensa actividade vulcânica, com mais de três dezenas de erupções vulcânicas históricas registadas.

Esta condição natural no Arquipélago, que evidencia uma enorme quantidade de energia endógena no subsolo, suscitou, desde meados do século XX, a ideia de se vir a explorar estes rearsos geotérmicos para a prooução de electricidade (fig. 2) .

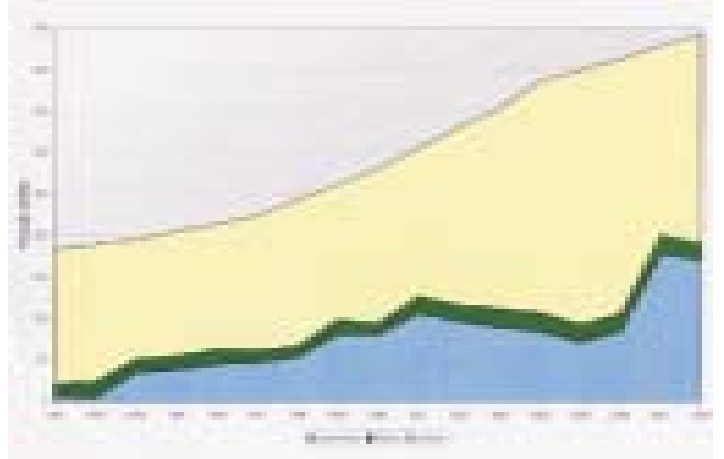

Fig. 2 - Evolução da participação das fontes de energia do sistema electroprodutor de S. Miguel (SOGEO - SOciedade Geotérmica dos Acores, S. A.) .

A azul escuro salienta-se a energia geotérmica.

Se por um lado esta energia é fundamental para as Açores, por ser uma energia limpa, por autro lado é de referir o facto de o Arquipélago se tomar menos dependente do exterior.

Em 1973, na ilha de S. Miguel, foi descoberto um reservatório geotérmico de alta entalpia com temperatura superior a $200^{\circ} \mathrm{C}$, durante a execução de uma sondagem geológica de investigação pela Universidade de Dalhousie do Canadá (fig. 3) . Este acontecimento desencadeou, ainda na mesma década, a exploração dos recursos geotérmicos na zona envolvente que culminaram, em 1980, com o arranque da $1^{\text {a }}$ Central Geotérmica Piloto do Pico Vermelho ou PV1.

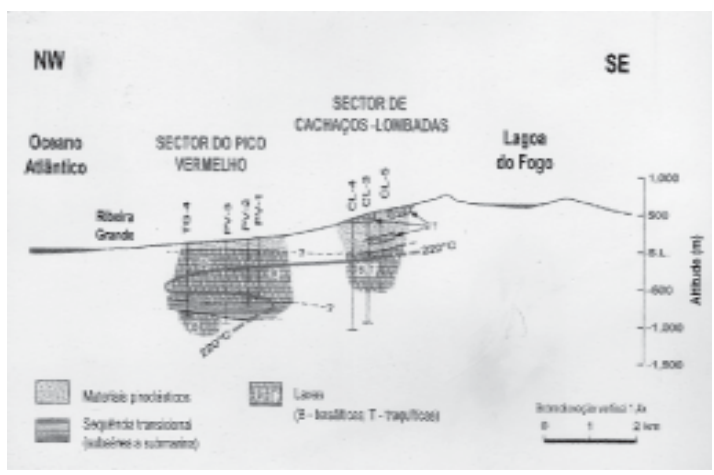

Fig. 3 - Perfil geológico do sistema geotérmico do Vulcão do Fogo (SOGEO/GeothermEx, Inc., 2002)
Em 1994, iniciou-se a exploração da Central Geotérmica da Ribeira Grande contando com a produção dos poços geotérmicos CL1 e CL2 que posteriomente, em 1998/2000 foi complementada cam as poças geotérmicas C3, C5 e CA4, este último convertido empoço de reinjecção (fig. 4) .

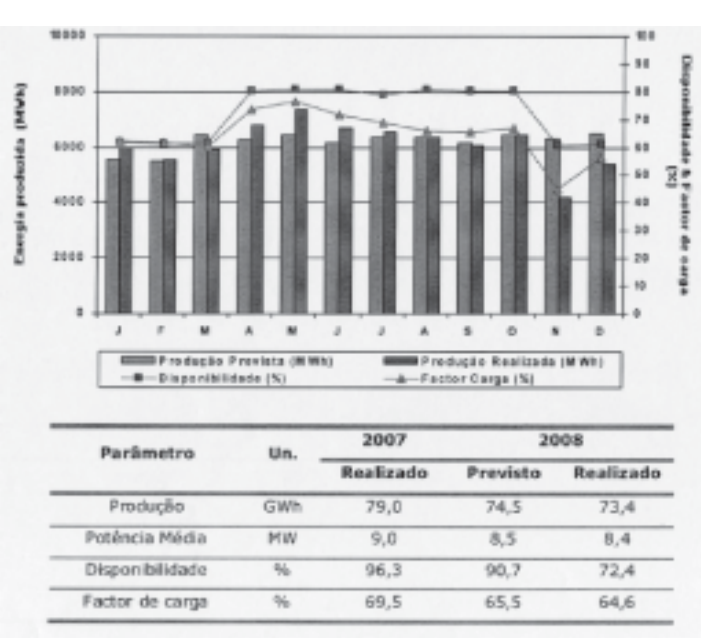

Fig. 4 - Indicadores de Exploração 2008 da Central Geotérmica da Ribeira Grande (SOGEO) .

A Central Geotérmica do Pico Vermelho, a primeira central geotémica a ser instalada na i lha de S. Miguel (Açores) , como projecto-piloto, tem uma potência nominal de 3 MV. En termos de historial de resultados de exploração, até 2001, a central produziu cerca de 73,5 GWh em mais de $121 \mathrm{mil}$ horas de funcionamento. Actualmente a sua produção amual é de cerca de 7 Ghh (fig. 5) .

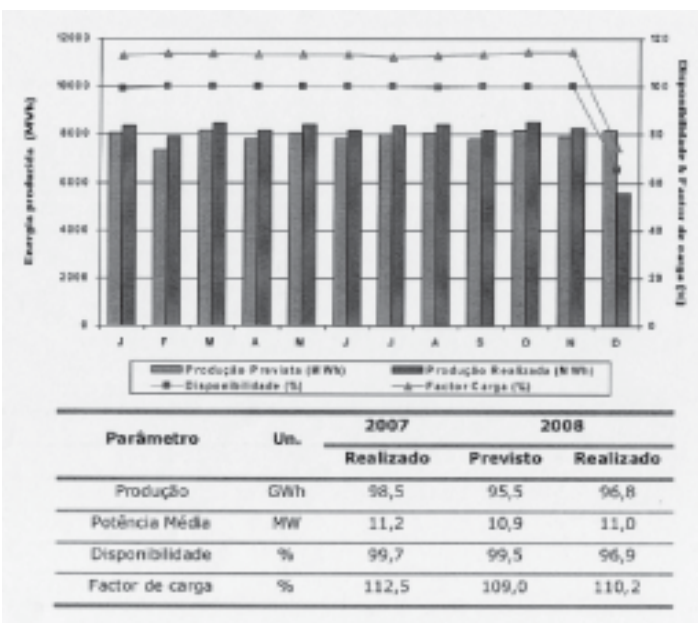

Fig. 5 - Indicadores de Exploração 2008 da Central Geotérmica do Pico Vermelho (SOGEO) .

A água e o vapor são conduzidos para permutadores para vaporização do fluido de trabalho normal - pentano que circula num sistema fechado. o grupo gerador está equipado com duas turbinas 
alimentadas a igual pressão, sendo o sistema de condensação através de aerocondensadores. Os poços PV4, PV7 e PV8 foram executados com o dojectivo de produzirem fluido geotérmico para a alimentação da Central, sendo os poços geotérmicos PV5 e PV6 destinados à injecção do fluido geotérmico, após troca de calor como fluido de trabalho (fig. 6) .

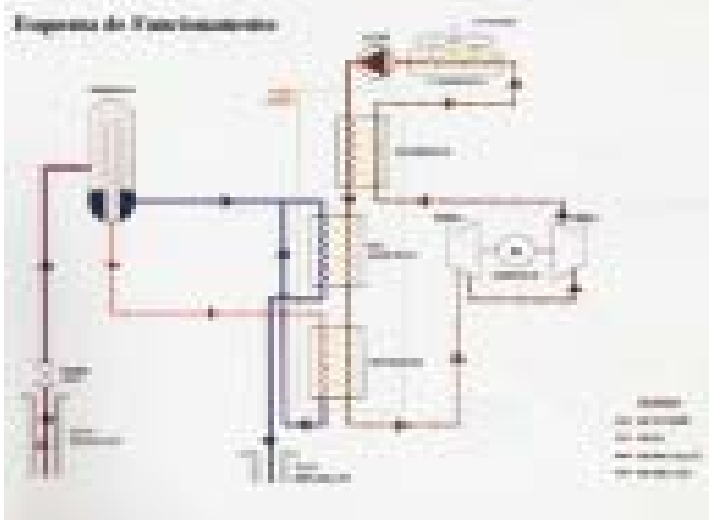

Fig. 6 - Esquema de funcionamento das Centrais Geotérmicas ORMAT: Ribeira Grande e Pico Vermelho (SOGEO) .

Além destes poças executados em 2005, a Central conta ainda com os poços geotérmicos PV2 e PV3 perfurados em 1980 e 2000, respectivamente. O PV1 que serviu durante 25 anos como central - piloto, é hoje utilizado como poço de monitorização do reservatório. A profundidade deste poço é de cerca de 1000 metros enquanto a dos de reinjecção é de 1374 metros (PV5) e de 1102 metros (PV6). A temperatura máxima é de $242^{\circ} \mathrm{C}$.

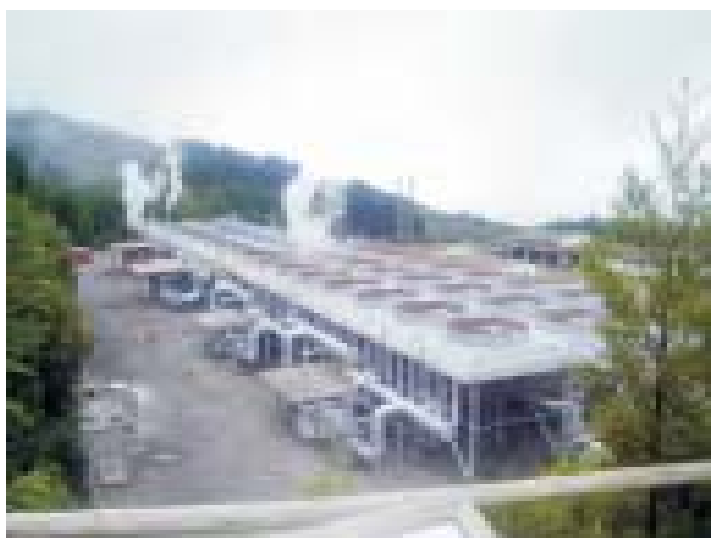

Fot. 1 - Enquadramento da Central Geotérmica da Ribeira Grande na Reserva Natural da Lagoa do Fogo.

A Central Geotérmica da Ribeira Grande (fot. 1) , situada a 550 m de altitude em reserva natural, passui uma capacidade de 13 MN e foi instalada em duas fases. A fase A, em 1994, constituída por dbis grupos turbogeradores e a fase B, em 1998, em que foi instalada uma potência adicional com mais dois grupos turbogeradores.
A tecnologia do equipamento usa um fluido orgânico intermédio para o qual é transferido calor do fluido geotérmico.

\section{Consequências ambientais da exploração geotérmica em S. Miguel}

Passados que foram 20 anos após o início dos trabalhos de perfurações com vista à exploração geotérmica na Reserva Natural da Iagoa do Fogo, na ilha de S. Miguel, impõe-se uma reflexão: Será que os erros que foram cometidos naquela época e contabil izados mais tarde serviram para não virem a ser repetidas em situações/empreendimentos posteriores?

Recuemos, então, 20 anos.

Decorria o Verão de 1988, quando, na Reserva Natural da Lagoa do Fogo, vertente norte do complexo vulcânico do Fogo, na bacia hidrográfica da Ribeira Grande, se iniciaram as doras conducentes à realização do poço geotérmico Ci1 (CachaçosLombadas) , a uma cota de 550 metros. Tais trabalhas nunca foram do conhecimento oficial da então Divisão de Ambiente da extinta Secretaria Regional do Equipamento Social, hoje Secretaria do Ambiente, não tendo sido feitos, portanto, previamente, quaisquer estudos de impactes ambientais, nem de previsão de riscos neste grande projecto.

O alerta foi dado quando, como geógrafo daquela Divisão de Ambiente, e sabendo do início das obras de preparação dos terrenos para a execução do furo geotérmico, nos deslocámos à zona, em Agosto desse mesmo ano, e verificámos que se procedia a tais trabal hos sem o mínimo respeito pelos valores naturais (fot. 2) .

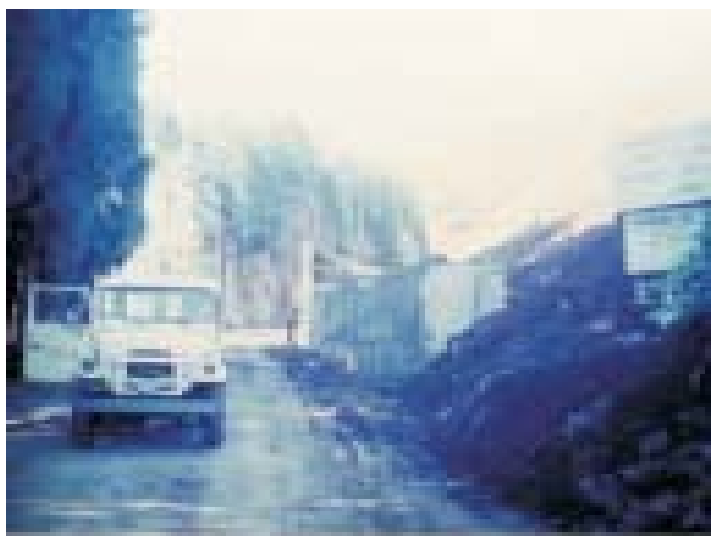

Fot. 2 - Alteração da paisagem na zona CachaçoLombadas (CL), onde se iniciaram as obras.

Enquanto as consequências que se fizeram sentir estiveram relacionadas "apenas" com a destruição do coberto vegetal, alteração do relevo, poluição das ribeiras e obstrução das mesmas, os acontecimentos nunca foram encarados com a devida 
atenção, e os técnicos da Divisão de Ambiente, ignorados como entidade informativa ou como especialistas na gestão dos recursos do ambiente físico, não erammais do que "fil lósofos" aja missão principal era travar o progresso.

Esta situação de despreocupação manteve-se até ao dia 17 de Novembro de 1988, dia em que a alteração dos caracteres físico-químicos e bacteriológicos da água de abastecimento público à cidade da Ribeira Grande, provenientes da captação do Chá Canto (nascente), surgiram alterados a ponto de a tornarem imprópria para consumo (fot. 3) .

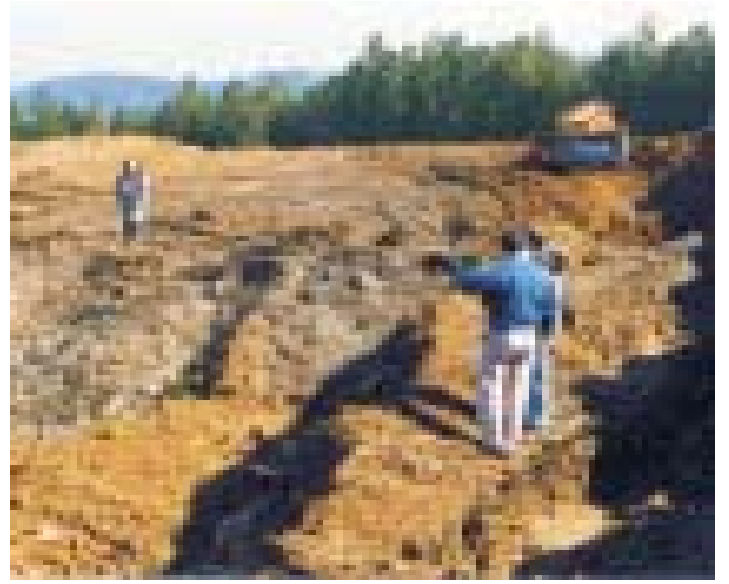

Fot. 3 - Contaminação das águas potáveis de abastecimento público.

Estas alterações conduziram ao aparecimento de água com aspecto leitoso, nada agradável à vista e absolutamente incompatível com os nobres fins a que se destina tão vital rearso.

Com a população a sentir, no dia a dia, as consequências de tão má gestão, a solução adoptada foi a de "bombardear" a comunicação social com variadíssima informação sobre o assunto.

Perante uma situação que não evoluía relativamente aos problemas apontados e contestados pela população da área, o desespero das entidades responsáveis pelo Projecto era de tal ordem que as técnicas da Divisão de Ambiente, foram, finalmente, chamados a participar numa reunião extraordinária, a 24 de Novembro, na Câmara Municipal da Ribeira Grande, com o dojectivo de darem um parecer sobre as acontecimentas.

Consideramos de interesse seguir o percurso do Projecto nos aspectos que, directa ou indirectamente, originaram a deterioração do ambiente para podermos fazer uma avaliação mais precisa da cadeia de consequências geográficas mais flagrantes.

\section{Consequências imediatas}

Ficou já referida a contaminação das águas potáveis de abastecimento público, tendo-se verificado que tal acontecia sempre que ocorriam grandes aguaceiros.

O material utilizado na broca para perfuração foi a bentonite, uma argila que, devido à sua granulometria, facilmente se introduzia nos terrenos, bastante permeáveis, indb atingir o lençol freático da nascente chá canto que abastece a cidade da Ribeira Grande. Além disso, e por existir grande quantidade de gado na área, os próprios excrementos foram transportados pelas águas das chuvas intensas de 1988/89. Facilmente penetraram nos terrenos removidos e atingiram a nascente, contaminando-a.

Assim, forramconstnúdos três grandes reservatórios para decantação da argila (fot. 4) , tendb a água sido posteriormente canalizada para a ribeira. Estes depósitos deveriam ter sido, em nosso entender, revestidas de cimento, a fim de evitar a infil tração e consequente contaminação das nascentes.

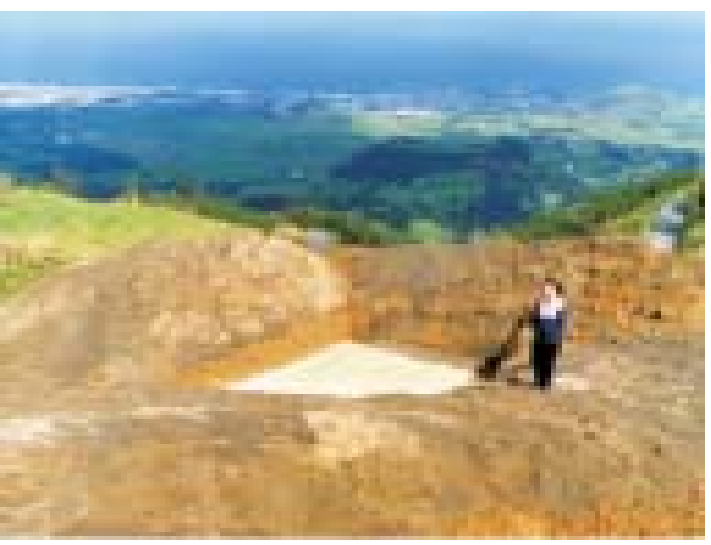

Fot. 4 - Aspecto de um dos reservatórios para decantação da argila.

\section{A crise sísmica de 1989}

A área onde foram executados os trabalhos, Lagoa do Fogo, não foi, quanto a nós, convenientemente escolhida.

A placa de betão do respectivo furo, situandb-se mesmo sobre uma câmara magmática, constituiu uma situação de grande risco, tanto mais que o furo foi executado na vertical até uma profundidade de 2000 metros.

Geralmente, em estudos especializados de geotermia, o local de perfuração é escolhido fora da área perpendicular à câmara e posteriormente é feita uma perfuração radial.

O Vilcão do Fogo é uma estrutura percorrida por várias falhas activas e autras potencialmente activas, 
situada na célebre falha que atravessa a Ilha na direcção NNO/SSE.

As últimas enupgões vulcânicas nesta área datam de 1563: uma estromboliana básica com emissões de basaltos alcalinos (mangearitos e havaítos) que soterraram a área urbana da Ribeira Seca da Ribeira Grande, na costa Norte da Ilha; a outra, no interior da caldeira, pliniana, traquítica ácida, com grandes quantidades de materiais panúticos (piroclastos) que cobriram toda a parte oriental da Ilha, soterrando ribeiras, tendo, nas proximidades da caldeira, as depósitos chegando a atingir mais de 15 metros de altura (fot. 5) , encontrandb-se actualmente, cobertos por uma fina camada de solo.

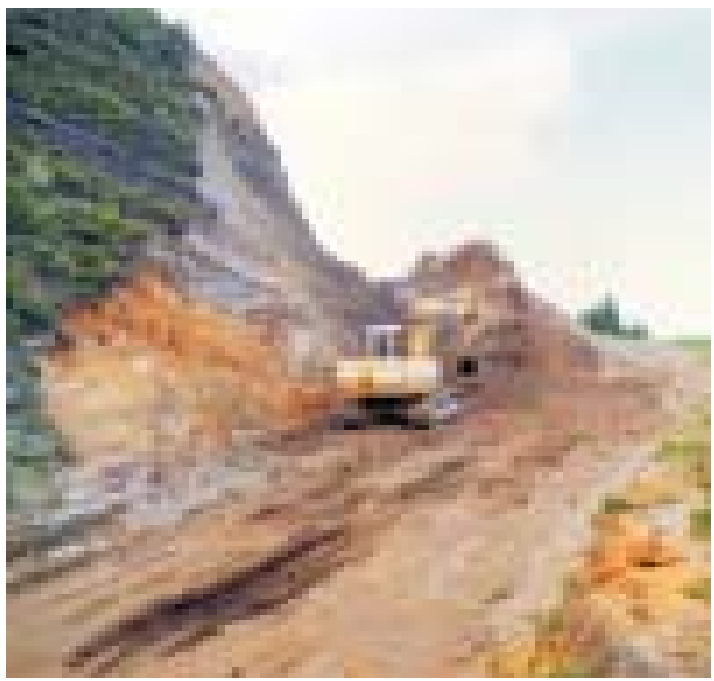

Fot. 5 - Materiais de projecção. A camada de solo é por vezes muito fina em algumas áreas da Reserva. Contudo, por baixo, existem grandes quantidades de materiais de projecção proveniente da erupção de 1563 com mais de 15 metros de espessura e em zona de acentuado declive.

Será possível afirmar que tenha havido alguma relação entre a crise sísmica de 1989 e a perfuração geotérmica?

Um vulcão activo, com todas as suas manifestações seaundárias de vulcanismo (fumarolas, caldeiras, etc.) funciona, grosso modo, como uma panela de pressão.

Se num dado momento, em que se encontra a funcionar normalmente, impedirmos que o vapor escape pela válvula, pressionando-a, estaremos a provocar um desequili íbrio em toda a estrutura, podendo mesmo originar fendas nas zonas mais frágeis.

Em nosso entender, foi o que aconteceu no Fogo. Às 5.45 h do dia 11 de Maio de 1989 presenciámos a abertura, pela primeira vez, do furo geotérmico. 0 vapor que começou a sair em grandes quantidades, terá provocado, um alívio de tensões anteriormente existentes no complexo vulcânico, em toda a sua estrutura e ao longo das suas falhas (fot. 6) .

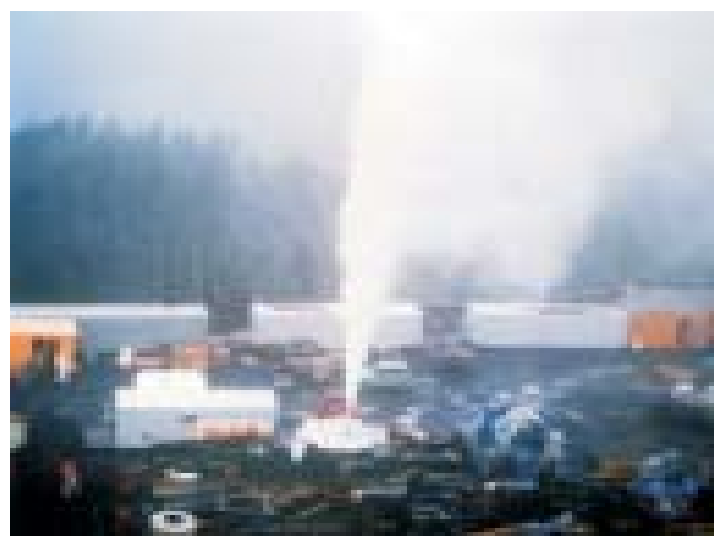

Fig. 6 - Abertura do furo geotérmico no dia 11 de Maio de 1989.

No dia 13 de Julho, a válvula de escape do vapor foi fechada e, casualmente ou não, neste mesmo dia começou a crise sísmica (ou vulcânica) na Lagoa do Fogo (fig. 7) .

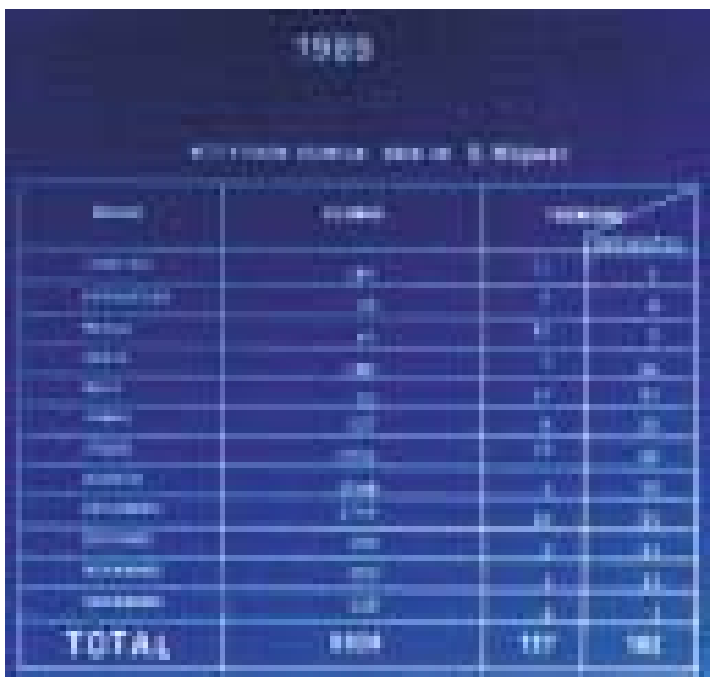

Fig. 7 - Actividade sísmica na ilha de S. Miguel durante o ano de 1989 (Centro de Vulcanologia da Universidade dos Açores) .

A 22 do mesmo mês, por ocasião de uma visita oficial ao empreendimento, o furo esteve aberto durante 24 he, neste períodb, a actividade sísmica decresceu de um máximo de 380 registos diários antes da abertura para 20.

No dia seguinte, tendo-se procedido, de novo, ao encerramento da válvula, aquele número voltou a aumentar substancialmente. A crise, neste períodb, atingiu o máximo de 1600 sismos/dia em princípios de Setembro, começandb, a partir daí, a dissipar-se tendo sido dada por extinta no dia 23 deste mês (analisar os registos da actividade sísmica nos meses de Julho a Setenbro da fig. 7 - Crise) .

Poderia ter surgido uma enupção freática nesta área devido não só à grande tensão provocada na estnutura, como à infil tração das águas que abundam 
no seu subsolo e que, em contacto com o magma, a poderiam ter originado.

Foi o que aconteceu, em tempas não históricas, bem perto do Fogo, como é o exemplo dos Maars da Lagoa de S. Brás e da Lagoa do Congro. Até hoje ainda não se sabe se teria sido uma crise sísmica ou vulcânica (fot. 7) .

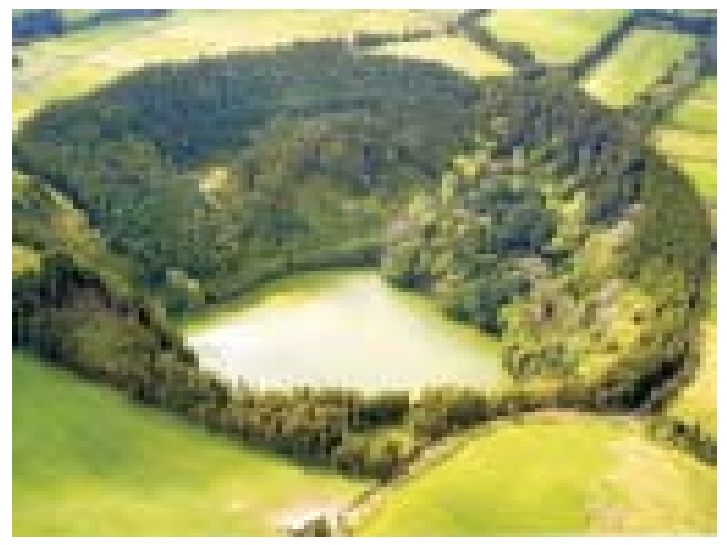

Fot. 7 - Maar da Lagoa do Congro.

Terá havido alguma relação entre a perfuração geotérmica e a crise sísmica? Tubb leva a crer que sim.

\section{As cheias e o alto risco de erasão do solo}

O local onde se situaram as trabalhos fica, sem dúvida, numa área onde as precipitações atingemvalores por vezes elevados. Alguns postos udométricos desta bacia registam médias amuais de 3300 l/m2 como é o caso do Mbnte Esarro a 810 m de altitude (fig. 8) .

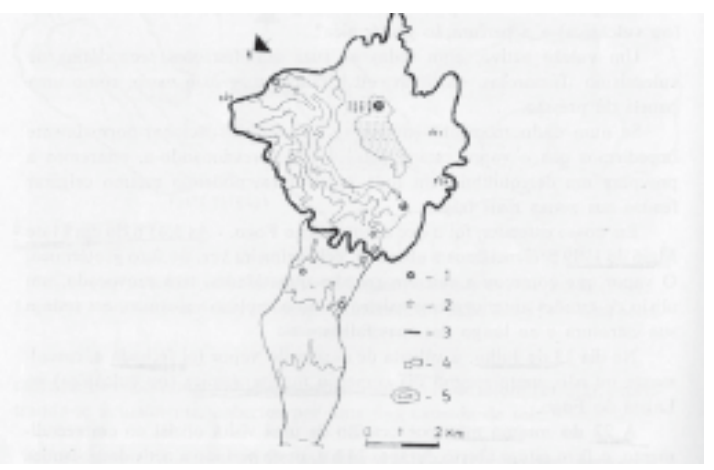

Fig. 8 - A Reserva Natural da Lagoa do Fogo e a respectiva bacia hidrográfica da Ribeira Grande: 1-Posto udamétrico; 2-nascente; 3-limite da Reserva Natural ; 4-furo geotérmico; 5-arvas de nível.

É de notar ainda que estes trabalhos se efectuaram a uma altitude de 550 m e que os Açores são afectados por tipos de tempo em que as intensidades das precipitações são bastante imprevisíveis. Os processas morfogenéticas ou morfoclimáticos, mais precisamente, são de tal gravidade, em especial nos meses de Inverno, que chegam a pôr em causa povoações situadas a jusante das ribeiras. No caso deste empreendimento, estamos no contexto da bacia hidrográfica da Ribeira Grande (fot. 8) .

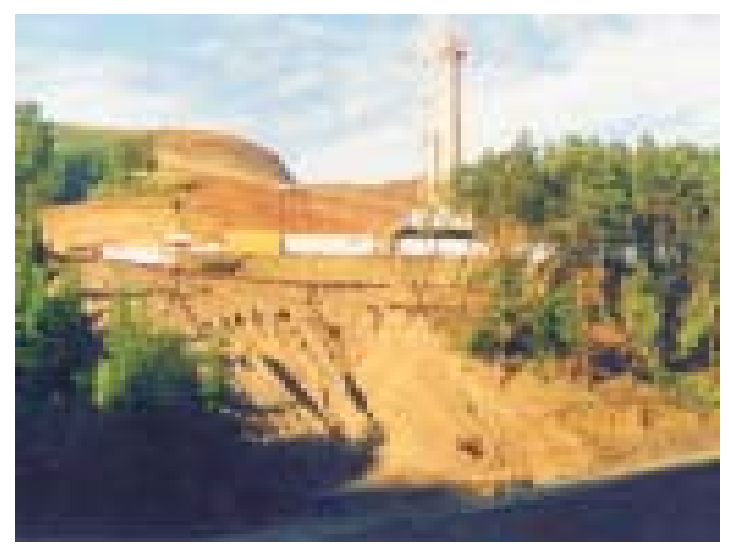

Fot. 8 - Área do furo e torre de perfuração geotérmica. Em primeiro plano, o leito da ribeira para onde foram lançados milhares de metros cúbicas de solo arável juntamente com árvores. Os ravinamentos são bem visíveis nesta fotografia

tirada após as primeiras chuvas de Outubro de 1989.

Não tinha sido ainda há muito tempo atrás que as populaçães da Povoação e Faial da Terra sofreram na carne os efeitos de tipos de tempo bastante característicos destas latitudes atlânticas: no ano de 1986 e só no mês de Setembro, o pasto udométrico, situado a 904 m de altitude na caldeira da Povoação, registau 740 l/m2.

As ilhas das Açores passuem ecossistemas muito frágeis e qualquer alteração, ainda que em escala reduzida, pode colocá-los em desequilíbrio, provocando tensões que o ambiente nem sempre pode comportar e situações imprevisíveis e até indesejáveis para as populaçães.

O que se verificou na vertente norte da Lagoa do Fogo, em particular, a movimentação de terras, a desarborização, a modificação no declive das vertentes e a dostnuçãono leito das ribeiras, teve um impacte decisivo nos ambientes inferiores.

A bacia hidrográfica da Ribeira Grande tem uma área e perímetro de $18500 \mathrm{Km} 2$ e 26640 km, respectivamente. Com uma densidade de drenagem de 4, 39 km/km2 apresenta uma certa predisposição para cheias.

Além deste factor natural, os seus declives são bastante elevados com uma média de 46\% (fot. 9) .

O seu solo e subsolo são de características bastante instáveis. Quando removidos ficamemperfeito desiquilíbrio provocando desabamentas. Deste facto são exemplo as movimentas de creeping, bem notórios na base dos troncos das árvores que abundavam na bacia.

Apontadas as consequências geográficas mais importantes deste empreendimento não podemos 


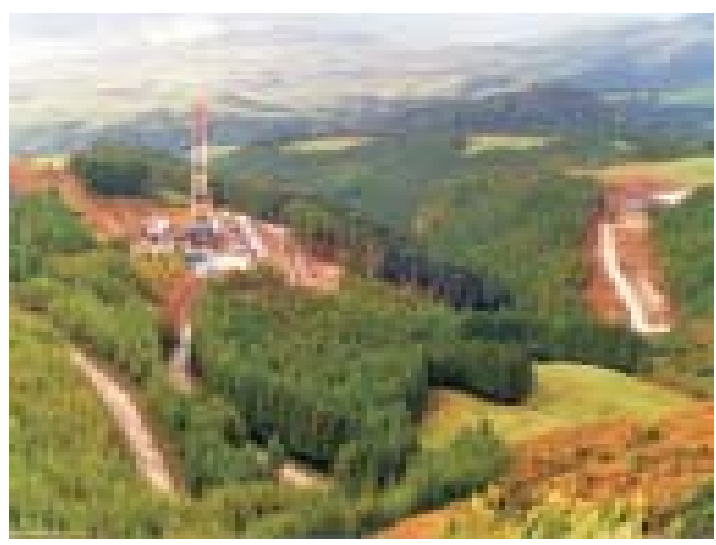

Fot. 9- Aspecto parcial da bacia hidrográfica da Ribeira Grande.

deixar de constatar que, infel izmente, se continua a actuar agora e a contabil izar amanhã.

Qual a situação no presente? Que projectos futuros de aproveitamento de recursos geotérmicos? Os erros que foram cometidos serviram para não voltarem a ser repetidos nas situações ou empreendimentos posteriores?

Presentemente, além das centrais geotérmicas na i tha de S. Miguel, já anteriormente referidas, na i tha Terceira foi seleccionada, em 1999, uma área de interesse geotérmico, local izada no centro da i lha, no Pico Alto, que promete suportar o desenvolvimento de uma central geotérmica de 12 MN.

Na ilha de S. Miguel, concluída a fase B da Central da Ribeira Grande e com a exploração do CL5 em 2000, a energia geotérmica contribui com cerca de 35 \% na estrutura da prooução da energia eléctrica da Ilha, representandb 18 \% do total do arquipélago.

$\mathrm{Na}$ ilha Terceira, de acordo com o que refere a Geo Terceira - Sociedade Geceléctrica da Terceira, " as indicadores dotidos com a perfurração dos poços geotérmicos de avaliação, PA1 e PA2, são promissores ao nível da temperatura medida no interior do reservatório, que excede os $300^{\circ} \mathrm{C}$, e da permeabilidade das formações geológicas atravessadas. No entanto não permitiram caracterizar o reservatório geotérmico de forma a suportar a decisão de viabi 7 idade técnico-económica do Projecto Geotérmico da Ilha Terceira. Fncontra-se já concluída. a fase final de prospecção e a execução dos poços profundas do Projecto. Verificando-se a viabilidade técnico-económica do aproveitamento do recurso, seguir-se-á a construção da Central, estandb previsto entrar em elaboração no final de 2011, com uma contribuição de 38\% na cobertura total da ilha. A estrutura actual de prooução da i lha Terceira, para um total de $129 \mathrm{GWh}$, conta com uma contribuição de energia hídrica de cerca de 3\%.

De acordo com o programa de perfuração do Projecto, está em curso, desde final de Março do corrente ano, a construção de três poças geotérmicos de prooução e de reinjecção, PA3, PA4 e PAS, com cerca de 1000 metros de profundidade, no Campo Geotérmico do Pico Alto.

A Terceira conta, a partir de 2006, com uma contribuição de renováveis de cerca de 56\% num total de 163 GWh, o que veio aumentar a autonomia energética da ilha.

\section{Conclusão}

Queremos deixar bem claro que nunca fomos contra o aproveitamento da energia geotérmica, pelo contrário, sendo uma energia não poluente sempre teve todo o nosso apoio. Só que o projecto foi mal encaminhado à nascença sem um estudo prévio efectuadb por uma equipa pluridisciplinar.

A situação descrita, ocorrida há 20 anos, pode ser considerada um exemplo de má gestão das novas tecnologias, em que não foram encarados e reconhecidos os efeitos secundários da sua aplicação. Neste exemplo foi bem visível a sequência risco, perigo, crise.

Tal não teria acontecido se, como introoução do projecto, tivessem sidb tomadas certas medidas e feita a caracterização física do espaço geográfico destinado a este empreendimento de grande envergadura.

Assim, o local dos trabalhos poderia ter sido escolhido fora dos limites da estrada que dá acesso à Lagoa do Fogo. A decisão tomada só se justifica por razões económicas, por ter sido muito mais rentável realizar o projecto junto à estrada do que ter de se abrir um caminho de penetração fora dos olhares daqueles que visitam uma das mais belas paisagens dos Açores.

De referir ainda o não aproveitamento dos mi thares de metros cúbicos de solo arável na recuperação das zonas de "biscoito" não muito distantes do local dos trabalhos. Foram, ao contrário, anarquicamente lançados à ribeira. A única explicação que encontrámos foi, uma vez mais, a de minimizar os custos do projecto, já que se tomou mais económico lançar a terra ali mesmo na ribeira do que ter de se percorrer aproximadamente $10 \mathrm{~km}$.

Assim, neste exemplo, e pelas situações de crise descritas, foi bemvisível a sequência risco, perigo, crise (L. FActites, 1990, citado por F. RHसO, 2005) .

Nos empreendimentos pasteriores realizados nas ilhas de S. Miguel e Terceira e anteriomente referidbs, já houve a preocupação de não serem cometidos os mesmos erros. Não houve portanto risco, logo não have crise.

Espera-se que, com o conhecimento das situações anteriores, o futuro da exploração geotérmica no Arquipélago dos Açores não volte a ser um exemplo 
da acção do Homem (acção antropogénica) que contribui, não só para a degradação do meio envolvente, mas ainda para a vulnerabilidade das populaçães da áreas adjacentes.

\section{Agradecimentos}

Agradeço ao Eng. Carlos Bicudo da Ponte, Coordenador Geral do Projecto ORMAT da SOGEO, pela cedência de dados e de toda a informação científica respeitante às Centrais Geotérmicas da Ribeira Grande e do Pico Vermelho, sem os quais não nos teria sido passível aprofundar as processas da Geotermia. Agradeço ainda todas as facilidades que me concedeu, por ter facultado um técnico da SOGEO que me acompanhou numa visita guiada às referidas Centrais.

\section{Referências bibliográficas}

FAlits, Lucien (1990) - "La dimension des faits et la théorie du risque" . Le Risque et la Crise, Malta, Foundation for Intemational Studies, p. 31-60.

FERNANDES, J. Guilherme de Campos (1985) - A Caldeira do Fogo - Génese e evolução das formas de relevo. Universidade das Açores, Ponta Delgada, $42 \mathrm{p}$.

Foriz, Victor Hugo (1997) - Algums Viloẽes da Ilha de S. Miguel. Ponta Delgada, Observatório vilcanológico e Geotérmico dos Açores, 160 p.

Lourenço, Luciano (1986) - "O rio Alva - Estudo hidrogeamorfológico". Cademos de Geografia, 5, coimbra, p. 43-123.

Peixoro, José Pinto (1987) - Influência do Homem no clima e no ambiente, Secretaria de Estado do Ambiente e dos Recursos Naturais, Lisboa, 160 p.

Rıposo, António G. B. (1989) - "A problemática da política ambiental" . Actas, V colóquio Ibérico de Geografia, Nov. 89, León, Espanha.

Rłposo, António G. B. (1990) - "As chuvas torrenciais de Setembro a Novembro de 1986 e suas consequências na Povoação e Faial da Terra". Ias Jomadas do Ambiente, 1990, Angra do Heroísmo.

Raposo, António G. B. (1998) - "Os desabamentos na Bacia Hidrográfica da Ribeira Quente e sua freguesia, na madrugada de 31 de Outubro de 1997". Açoreana, 8 (4), p. 571-590.

REBELO, Fernando (1985) - "Identificação dos processas erosivos actuais na parte ocidental da ilha de S. Miguel (Açores)" . Cadernos de Geografia, 4, Coimbra, p. 121-139.

REBELO, Fernando (2005) - Uma Experiência Europeia em Riscos Naturais, Minerva Coimbra, Coimbra, $123 \mathrm{p}$.
RFBrio, Fernando; RAPOSO, António G. B. (1988) "As inundações de 2 de Setembro de 1986 na Povoação e Faial da Terra (S. Miguel - Açores)", Cademos de Geografia, , 7, Coimbra, p. 169-179. SOGEO (Sociedade Geotérmica dos Açores, S. A.) - Geotermia em S. Miguel. Central Geotérmica da Ribeira Grande, Ponta Delgada, 8 p. 